\title{
From The Painted Veil to Its Screen Version: The Changing Journey of Salvation and the Unchanging Spiritual Destination
}

\author{
Yitong Pan $^{1}$ \\ ${ }^{1}$ Academy of Drama, Film and Television, Communication University of China,Beijing 100024, China \\ Corresponding author Email: $20160501 @$ stu.nun.edu.cn
}

\begin{abstract}
In the film adaptation of Maugham's novel The Painted Veil, the film and television presentation of the protagonist's psychological activities and the change of the protagonist's image are two issues worth exploring. Based on the theory of haptic visuality and narratology, this paper focuses on the redemption journey of the heroine and explores the heroine's psychological changes and the image of the hero in the film.
\end{abstract}

Keywords: The Painted Veil, William Somerset Maugham, film adaption, haptic visuality, narratology

\section{INTRODUCTION}

The Painted Veil is a novel written by William Somerset Maugham, which was published in 1925.The story tells how the heroine Kitty completes selfreflection and redemption step by step from an empty, superficial, vain woman, and finally gains inner peace.

This novel is not Maugham's most well-known one, but it has been adapted into a film three times, and the most famous one is the one directed by John Curran, which was released in 2006. The original novel has a strong realistic color, and has a profound reflection on human nature and desire. On the premise of not losing the essence of the original work, considering the transformation of audience and media, the film romanticizes the work, and shows the psychological description in the original work in a more intuitive way.

\subsection{Related Work}

At present, there are three kinds of researches on the novel and film of The Painted Veil.

\subsubsection{The Study of Orientalism and Colonialism}

Researchers focus on the otherness of the Chinese image in The Painted Veil, pointing out that the work has Utopian reverie about China and defines the Chinese as barbaric rescued, which is full of Orientalism bias. For instance, ZHAO Xuan's "Three Film Texts and the Oriental Complex: an Imagologie Interpretation of Memoirs of a Geisha, The Painted Veil and Babel', employs Edward Said's Orientalism theory to argue that China in the novel and film The Painted Veil is only a foreign space for the creator, and its function is only to provide some foreign feelings, rather than to show the real image of China. [1] LIANG Qing's "China Under the Veil: A Comparison of the Image of China Between Maugham's Novel The Painted Veil and the Film Adaption" shows that Maugham's original work is full of imperialist gaze on China, and the Chinese people are in a state of aphasia collectively, which can only be represented by the author. [2] The film is more objective and fair to examine China, through the specific depiction in order to more truly show China. In "Imperialist and the Demystified Orient: Semicolonial China in Nineteenth-Century English Literature", Tamara Wagner explores the colonial Criticism and Orientalism from the perspective of commerce and trade. [3] She believes that the renegotiation of foreign affairs in The Painted Veil self-consciously plays with the ends (and potential dead ends) of any orientalist and/or imperialist fantasy concerning China.

\subsubsection{The Study of Film Adaptation}

By comparing the similarities and differences between the two, researchers analyze the use of audiovisual language in movies, and explores the gains and losses of the visualization of literary classics. LUO 
Ying's "The Veil Waiting to be Lifted by Men" explores the embodiment of male chauvinism in the film from the perspective of camera language. [4] QIN Yongxia's "An Analysis of the Old Town through the Space Lens in the Film The Painted Veil" focuses on the transformation of space lens and the influence of light and shadow art on the overall tone of the film, which changes the depression and gloom in the original work into a romantic and warm atmosphere. [5] In "Transgressing the Spaces in Film Adaptation of W. Somerset Maugham's The Painted Veil', Agnieszka Kurzawa explores the use of image language in the film on the construction of gender space. [6]

\subsubsection{The Study of Cross Culture and Chinese Image}

In "The Construction of Chinese Image of Western Centralism in Maugham's The Painted Veil in the Context of Western Culture", considering the phenomenon that the image of China in Maugham's works hovers between Utopia and vulgar ugliness, the researcher deeply analyzes the western centralism perspective of privilege and Maugham's own view of China. [7] In the cross-cultural perspective, the researchers analyze the religious thought, cultural comparison, Chinese image in The Painted Veil. MAI Xin's "The Image of China Under the Veil-a CrossCultural Interpretation of the Image of China in the Film The Painted Veil" deeply analyzes the presentation and thinking of the image of China in the film. [8] LU Manli's "Under the Veil: an Analysis of Cross-Cultural Factors in the Film The Painted Veil" explores the cultural conflicts and invasion between China and the west, as well as the communication and collision between cultures. [9]

\subsection{Paper Structure}

At present, there is little research on The Painted Veil, especially the film adaptation. Based on the previous studies, this paper focuses on the same theme and different ways of salvation of novels and movies, and makes an in-depth analysis by using the relevant theories of haptic visuality and narratology.

\section{DISCUSSION}

\subsection{The Inner Struggle of the Characters from the Perspective of Haptic Visuality}

In the film adaptation of literary masterpieces, how to transform psychological activities into visual images has always been a big problem. Redemption is an important theme in Maugham's novel. How the protagonist Kitty gets rid of the original emptiness step by step, from filling her heart with lust and not knowing the direction of life to being rich and firm in deep and truly possessing peace and strength, is shown by a lot of psychological description. Readers can feel Kitty's struggle and depression, transformation and growth from the text, so as to realize the theme of redemption. However, the film is an art of audio-visual language, and a large number of words will not appear on the screen. In order to show Kitty's inner world and let the audience feel her salvation, the film achieves this effect by means of haptic visuality.

In western film theory, film has always been regarded as a visual art. The film theory has formed the thinking paradigm of "vision-centered", that is, the process of appreciating the film is mainly the function of vision. Vision has priority and independence, which is higher than hearing and touch. However, since the 1980 s, there has been an ideological trend of "sensation shift" in western films. In 1981, Gilles Louis Réné Deleuze put forward the aesthetic point of view centered on the most direct feeling of the body in Francis Bacon: the Logic of Sensation. [10] He goes on to throw out the theory of haptic visuality, that is, because as vision itself finds a haptic function in itself, and this function is separated from its visual function and belongs only to itself. To a certain extent, this view negates the theory of "vision-centered" throughout the classical and modern times, and emphasizes the need for direct "touch" in the creation and appreciation of films, not only for the eyes to see the image, but also for the body to touch the real object.

In the movie The Painted Veil of the same name adapted from Maugham's novel, which was released in 2006 , the application of haptic visuality is very subtle and has a good effect on the psychological display of the characters. In Maugham's novel The Painted Veil, the process of Kitty's step-by-step ideological transformation is shown by a large section of psychological description. These words are very delicate, which can make readers deeply experience her mental process in the process of reading. However, a large section of psychological description cannot be displayed on the big screen. If narration and voice over are used to explain, the film will be long and boring. In the transformation from words to images, the creators of the film The Painted Veil adopt a very delicate technique. The director refines the process of Kitty's psychological changes into four main stages, and each transformation was shown in concise and accurate lens language. These lens languages contain the idea of haptic visuality, which can make the audience not only see Kitty's expression changes visually, but also deeply appreciate her psychology and feelings.

At the beginning of the film, Kitty is a vain and superficial woman. Her heart is very empty. She has a shallow view of the world and has no more experience of life. She spends her time in the party, focusing on gossip and games. As Kahlil Gibran writes in Sand and 
Foam, "The second time when I saw her limping before the crippled", Kitty feels very empty and lonely after she marries Walter, whom she doesn't fall in love with but just intends to escape from her mother. [11] At this time, the romantic Charlie appears in her life and seduces her. Kitty is obsessed with Charlie's flirtation and has an affair with him. Kitty's mental state at this stage is most obvious in the group of scenes in which she has sex with Charlie. Laura Marks defines "haptic visuality" as a visuality that functions like the sense of touch by triggering physical memories of smell, touch, and taste, which $\mathrm{s}$ to explain the newfound ways in which intercultural cinema engages the viewer bodily to convey cultural experience and memory. [12] In the film, when Kitty and Charlie are making love, their bodies are in close contact. Kitty's sweaty body and the delicate texture on her skin are very clear under the camera. The audience not only sees Kitty making love visually, but also feels her excitement and indulgence, filling themselves with desire. They can't see the flow of emotion in making love, but just the intense entanglement of two bodies, full of strong desire. In the construction of haptic visuality, the character activities on the screen surface give the audience a "skimming sense", Laura Marks and the audience's eyesight touch Kitty's body, which is not only the participation of vision, but also the mobilization of multi-sensory common appreciation and feeling, so as to be more able to enter the hearts of the characters. [13]

With the development of the plot, Kitty follows Walter to MeiTanFu, where cholera is rampant. For the first time, she sees the dead people, the lonely children, the real suffering of life, all of which is quite different from the city where she used to live, and it also gives her a tremendous shock. In this situation, Kitty's mood has changed a lot, especially in her attitude towards Walter. At first Kitty deems Walter as a dull man, but when he comes to MeiTanFu, Walter's kindness and benevolence are gradually revealed. Kitty gradually senses Walter's virtues and changes her opinion of him, and begins to think about the significance of her own existence and the value that she can bring to others.

In this stage, Kitty's psychological change is mainly reflected in her seeing Walter fall asleep on the table when she delivers dinner to him at night after hearing the nun says how to help patients and how much she likes children. Giuliana Bruno argues that humans should shift their attention from optical gaze to haptic materiality and human being's mutual contact with objects or the environment occurs on the surface of the medium which is the interface. [14] She stresses that the screen itself plays a crucial role in the transmission of the film. As far as characterization is concerned, the psychological, emotional and other internalized factors of the characters can be displayed on the screen as if they were painted on cloth, which not only makes the audience see with their eyes, but also makes them touch and feel with their bodies. When Kitty saw the sleeping Walter, the soft light and shadow are interlacing, as if woven into a soft cloth. Kitty slowly approaches Walter with her lantern and looks at his sleeping face. At this time, time sways, as if Kitty's heart is touched, trembling and becoming soft. She gazes at Walter again. Instead of focusing on the vain and lustful things, she injects emotion and tenderness into her eyes. The surface of the screen brings materiality to the picture, which makes Kitty's psychological change not only stay on the expression or lines, but cast on a canvas woven by light and shadow. Haptic visuality realizes the virtual thing of "psychology" and turns it into tangible material. It also makes the audience have a deeper understanding of Kitty's inner changes.

The third change takes place when Kitty is taking care of the orphans in the monastery. Moved by Walter's benevolence and generosity, Kitty begins to reflect on her own shallowness. She is eager to find a way to prove her value, therefore in the process of taking care of her children, she gradually finds her value and what she really loves and cares about. Jennifer Barker believes that film is tactile. [15] She sets Andrei Tarkovsky's Mirror as an example. In the opening scene of the film, the shadow of a moving arm microphone is visible on the upper left corner of the wall behind the stuttering boy's body. Barker points out that this is the most obvious evidence of the existence of the "body of the film". [15] The body of the film actively expresses its attention and shooting attitude like the actor and the audience. The trembling microphone in the mirror is exactly the movie that feels the tension of the character, thus shaking like a human body. In the process of watching movies, like human body, movies can mobilize muscles, joints, skin system and other senses to truly touch and feel the stories and emotions in the movies. In the scene where Walter sees Kitty playing the piano for the children, Kitty is playing a cheerful tune, and the children are dancing around Kitty happily. In the close-up, the faces are crisscrossed. In the following panoramic shot, the children surround Kitty tightly. The children's dancing shadows are dancing on Kitty's face. It is the film that feels Kitty's joy and happiness at this time. The audience seems to be in the middle of it, deeply experiencing Kitty's happiness surrounded by children at this moment. In Vivian Sobchack's view, film is an active participant in perception and expression. [16] Panning, close-up, and light and shadow are all the expressions of joy, warmth, and fullness that the film perceives. They are also the changes in Kitty's heart that the film perceives, so that it can cheer for them.

When Kitty discovers her value and finally finds something that can make her happy rather than just satisfy her desire, she falls in love with Walter. This kind of love is different from the illusory desire for Charlie, but extremely serious and sincere. After Walter 
saves Kitty, who is besieged by the Chinese, Kitty also completes her redemption in the scene of adultery. She has grown up from a vain girl to a woman really finds value, recognizes love and has inner peace and happiness. Different from the indulgence and gratification of desire when Kitty and Charlie have an affair at the beginning of the film, Kitty and Walter are full of true feelings when they have sex. They hug each other, and Kitty is touching Walter's cheek. In the closeup, Kitty's texture and skin are clear and perceptible. Her seriousness and piety when she is making love with Walter are also deeply felt. At this time, "the skin of the image" no longer conveys Kitty's sexual desire and love. Kitty's body and close-up of micro expression are guiding the audience to "pay close attention to the composition of the image", create a sense of texture, and mobilize the audience's participation and sensory response to the "film image". [17] When the image passes through the vision, the audience will be closer to Kitty, so as to feel her sincere love for Walter and the real richness and warmth of her soul.

So far, Kitty has completed her salvation. After falling in love with Walter again, her heart becomes soft and calm. She begins to joke with Song Qing and shows excitement and curiosity when watching the water wheel with Walter. Her eyes no longer stay in the infatuation, but on the fields, lakes, green fields with love and softness. At the end of the film, when Kitty takes her son to buy flowers, she runs into Charlie but refuses his offer to deeper conversation. She is no longer the empty and superficial woman bewitched by desire, but a really kind, benevolent and peaceful person.

\subsection{Redemption from Love from the Perspective of Haptic Visuality}

In the original novel of the The Painted Veil, narrative perspective focuses on Kitty, and describes in detail how Kitty completes his redemption. There are not many parts about Walter in the book, and there is no detailed description of Walter's psychological changes. In the relationship with Kitty, Walter does not grow up obviously, but resents Kitty until he dies. The keynote of the novel is cold and sharp; however, the film changes the theme, weakens the criticism and reflection of human nature, and strengthens the theme of salvation. Moreover, in order to make the narrative compact, the film has deleted many branch plots in the novel, and has focused the main narrative plots on the love line between Kitty and Walter. By depicting the couple from not knowing each other and hating each other, they gradually move towards mutual recognition and true love. In love, especially Walter, both husband and wife get spiritual salvation.

The narrative perspective of "internal focus, external focus, no focus" is proposed by the French literary critic Gerard Genette. Unfocused means that the narrator is higher than the characters in the play and tells the story from a decentralized and omniscient perspective. [18] Cohesive focus is to tell the story in the eyes of a character from his psychology. In the original novel, most of the writers describe the plot from a non-focused narrative perspective, and fully explain the environment, process and result of the event. When describing the characters' psychology, it almost only shows Kitty's psychological activities from the perspective of inner focus. This narrative perspective can clearly show Kitty's redemption process, but Walter is basically in a state of aphasia, and he can't let go until death. The film tells the story from the perspective of male and female respectively, focusing on the process of their common salvation. Walter's journey of salvation is gradually taking place in his love with Kitty. As Kitty and Walter understand and cherish each other more and more, his soul has been saved and recovered.

In the first half of the movie, Kitty's subjective scenes are always in the majority. Walter doesn't give too many subjective scenes. However, after a quarrel between them in MeiTanFu made Walter begins to reflect upon himself, a large number of subjective scenes appear in the film, which fully show his psychological process of salvation. During the quarrel, Kitty says that she feels worthless in front of Walter and breaks into tears when she walks out of the room. At this point, in the middle shot, Walter looks thoughtful. This is the first time he has shown a big change in his mood. Previously, Walter's appearance is mostly expressionless, which makes it difficult to understand what he thought. Although Walter doesn't get growth and salvation at this time, he begins to reflect on himself and gradually opens his heart. After the quarrel scene, Walter no longer appears as a cold, pedantic person. He is not only in Kitty's field of vision, but also has a lot of subjective lens. The subjective lens use the camera instead of the characters' eyes to show the image they see. In movies, the use of subjective lens plays an important role in showing the inner feelings of characters.

After quarrelling with Kitty, Walter's increasing subjective lens also indicates that his heart is gradually opening up and changing. Walter's second impression of Kitty changed when he comes across her in the corridor. From Walter's subjective perspective, the audience can see Kitty's back in a hurry to take care of her children. This subjective shot of Walter adopts the method of depth of field. The foreground is Kitty who leaves in a hurry, and the background is Walter who looks at Kitty's back. When refers to the function of depth of field, in the small scene of Walter watching Kitty leave, Kitty and Walter are two prominent subjects. Kitty's leave highlights that she has gradually become rich and begins to find the sense of strength of existence value, and Walter's long gaze also shows his touch on Kitty's change. It is because Walter's impression of Kitty has 
changed, and he feels her gradually enriched heart. He also further opens his heart to Kitty, and ushers in his second growth in love, which is also a great salvation.

After persuading the villagers to bury their bodies and other incidents, Walter feels helpless and depressed. $\mathrm{He}$ is not sure whether his persistence was correct, and he is frustrated that his saving heart is not understood and recognized. In a conversation with Kitty in the evening, he shows his helplessness to Kitty for the first time, telling her that he doesn't know whether the decision to turn off the only water supply in the town was right. Although Kitty doesn't respond positively to him, and even jokes that they have something in common now, and they are both worthless people, Walter gets inspiration when Kitty is blowing the blower and builds a water tanker that could purify water. two scenes built from Kitty's blower to water wheel use the transition of similar scenes. From windmill to waterwheel, the picture is full of visual impact, and does not feel abrupt. This also clearly shows Kitty's help to Walter. After opening his heart to Kitty, Walter gets unexpected joy. However, the redemption that love brings to Walter is more than that, and he gains the happiness and freedom that he hasn't seen for a long time. Both of them are worthless people, which may also be said that Walter and Kitty have both disadvantages and advantages. He is neither superior nor inferior. Slowly opening his heart, Walter begins to show a lively, naughty and childish side. The film then gives Walter a set of subjective scenes, showing him looking at the water wheel, happily walking on tiptoe, walking in the endless wheat field, and accidentally falling. This set of shots clearly shows Walter's change. At this time, his world is no longer only full of rationality, but has an interest in natural vegetation, and his heart has gradually become soft and cheerful. Later, the relationship between Walter and Kitty gradually heats up.

Next, the director explained the change of the relationship between Walter and Kitty with two obvious changes of position relationship, and revealed Walter's inner salvation and growth. The first change of position took place in the scene of Walter watching Kitty playing the piano in the monastery. When Walter encounters a wall at Yuan Shikai's place, he sees Kitty playing the piano for the children. Previously, in addition to the first meeting, most of their positional relationship was that Walter walked in front and Kitty followed. Kitty watched Walter's back, but in this group of shots, Walter watched Kitty's back for a long time. It's not like Walter's brief and curious gaze at Kitty when he meets her in the corridor. This time, it's really a long gaze. Moreover, the picture flashes back to the time when they first meet. Walter regains his love for Kitty and rekindles his love for her. When the long repressed love comes back to Walter's body, he has a deeper understanding of Kitty. He no longer regards her as a "second rate" and regards her words as useless play language, but further grows up from Kitty. So far, Walter's impression of Kitty has changed completely. He begins to accept Kitty, appreciate Kitty and get more nutrients from her.

After that, their positional relationship changes again. In the debate about nuns' attitude towards orphans, Walter and Kitty sit close and almost side by side. Previously, the two were far apart, and mostly appeared in a diagonal position. This shows the close psychological distance between them, and they are more accepting of each other. It is in this scene that Walter's heart has changed greatly because of Kitty. His cold and rational side melts in Kitty's warmth. Walter put down his hatred and became a tolerant and warm man. In this argument between Walter and Kitty, Walter finally gets his inner salvation, from an over rational person to a tolerant person who can reconcile with himself and others. When Kitty tells Walter that the nuns of the monastery are great at helping orphans, Walter says that they do it for their own benefit and want their children to believe in Catholicism. However, Kitty refutes him. She thinks that people can't be perfect. Some defects and flaws are not difficult to cover up their essential goodness and light. In her eyes, even though nuns may have some selfishness, their love for children is sincere and admirable. After hearing these words, Walter really let go of his harsh demands and resentment towards Kitty, and realizes that he should not look for the quality that the other party does not have in love. When Kitty is pregnant with a child that may not be her own, Walter no longer entangles in her affair with Charlie, but hugs Kitty after a short hesitation. When he comes to the end of his life infected with cholera, he doesn't compare his death to a dog's death with resentment and unwillingness like in the book. Instead, he sincerely says "forgive me" to Kitty.

In this love, Walter opens his sealed heart, puts down his hatred and paranoia, abandons his excessive rational thinking, fills his heart with temperature, and completes his reconciliation with himself and others.

\section{CONCLUSION}

Starting from the theme of "salvation", this paper uses the theory of haptic visually to explore how the heroine Kitty's four obvious psychological changes are presented in film and television, and how to change from emptiness and confusion to peace and tranquility. At the same time, this paper focuses on the analysis of the hero Walter in the film is different from the image of the novel, through the narrative theory and lens language analysis to explore the process of redemption in love. 


\section{REFERENCES}

[1] Zhao Xuan. "Three Film And Tv Texts And An Orient Complex: A Comparative Literary Imagological Interpretation Of Memoir Of A Geisha, Veila And Babel." Film Literature.13(2007):34-35. DOI: CNKI:SUN:DYLX.0.2007-13-014

[2] Liang Qing. "China In The Veil: a Comparison Between Maugham's Novel Of The Same Name And The Film Of China." Film Review.16(2008):21-22. DOI:10.16583/j.cnki.521014/j.2008.16.052.

[3] Tamara S. Wagner, Imperialist Commerce and the Demystified Orient: Semicolonial China in Nineteenth-Century English Literature. Postcolonial Text 6, no.3 (2011): 1-17.

[4] Luo Ying. "The Veil Waiting to be Unveiled by Men." Film Literature.01(2008):82. DOI:CNKI:SUN:DYLX.0.2008-01-049.

[5] Qin Yongxia. On The Spatial Shot Shape Highlighting The Implication Of The Ancient Town In The American Film The Veil. Film Review.10(2012):28-30.

DOI:CNKI:SUN:DYPJ.0.2012-10-016.

[6] Agnieszka Kurzawa, Transgressing the Spaces in Film Adaptation of W. Somerset Maugham's The Painted Veil, DOI: http://dx.doi.org/10.18778/8142-006-8.09

[7] Lei Zhang. The Construction of Chinese Image of Western Centralism in Maugham's the Painted Veil in the Context of Western Culture. WOP in Education, Social Sciences and Psychology. Ed.. Francis Academic Press, 2020.

[8] Mai Xin. "The Image of China Under the Veil -- A Cross-cultural Interpretation of the Image of China in the Film The Veil." Journal of Xichang University (Social Science Edition.25.02(2013):5355. DOI:10.16104/j.issn.1673-1883.2013.02.023.

[9] Lumanli. "Under the Veil: An Analysis of Crosscultural Factors in the Film 'The Veil."' Short Story (Original Version).23(2016):116-117. DOI:CNKI:SUN:DPXS.0.2016-23-055.

[10] B. Meyer, Applying "Design by Contract", Computer 25(10) (1992) 40-51. DOI: https://doi.org/10.1109/2.161279

[11] Gilles, Deleuze, Francis Bacon: The Logic of Sensation. Continuum, London, 2005.

[12] Kahlil Gibran, Sand and Foam. Beijing: Beijing October Literature and Arts Publishing House Press, pp:175.
[13] Laura U. Marks, Haptic Visuality: Touching with the Eyes, in Finnish Art Review, 2 (2004), pp.7884.

[14] Giuliana Bruno, Atlas of Emotion: Journey in Art, Architecture, and Film, New York: Verso, 2002, pp. 21.

[15] Jennifer M. Barker, The Tactile Eye: Touch and the Cinematic Experience, Los Angeles: University of California Press, 2009, pp.10.

[16] Vivian Sobchack, The Address of the Eye: A Phenomenology of Film Experience, Princeton: Princeton University Press, 1992, pp.10.

[17] Laura U. Marks, The Skin of the Film: Intercultural Cinema, Embodiment, and the Senses, Durham: Duke University Press Books, 2000, pp.xi.

[18] Gerard Genette, The Narrative Discourse. Ithaca, Cornell University Press, 1983, pp.126. 